\title{
LONDENSE AANKOPEN VAN J.C.J. DRUCKER
}

Belangstelling voor de kunsten uit Azië kende in de Westerse wereld van het eind van de $19^{\mathrm{e}}$ en het begin van de $20^{\mathrm{e}}$ eeuw vele verschijningsvormen, ook in Nederland. Met de oprichting van de Vereniging van Vrienden der Aziatische Kunst in 1918 schaarden de échte liefhebbers van échte Aziatische kunst zich onder één paraplu. Maar daarnaast waren er mensen die zochten naar een universeel religieus gevoel dat sprak uit zowel Westerse als Oosterse kunst, er waren volgelingen van H.P. Bremmer (1871-1956) die naar estetische kwaliteit in kunstvoorwerpen zochten en daarbij over alle grenzen en tijdvakken heen keken. En er waren mensen die dachten dat ze zich voor Aziatische kunst interesseerden, maar eigenlijk verzamelaars waren van het eigen nationale verleden: de verzamelaars van het Chinese porselein dat VOC en particuliere handelaren in de $17^{\mathrm{e}}$ en $18^{\mathrm{e}}$ eeuw massaal naar Nederland hadden verscheept.

Het onderscheid tussen de groepen was natuurlijk niet zo absoluut, er waren Bremmerianen, aanhangers van mevrouw Blavatski en traditionele porseleinverzamelaars lid van de Vereniging van Vrienden der Aziatische Kunst, maar het was voor de Vereniging van belang de eigen missie 'haar volle aandacht te richten op de aesthetische waardering van die voorwerpen, welke om hun schoonheidswaarde als Kunstwerken moeten worden beschouwd"1 goed in het vizier te houden en daar paste een gezond wantrouwen tegen andersdenkenden bij.

Over een zo'n andersdenkende, J.C.J. Drucker, gaat dit artikel. Jean Charles Joseph Drucker (1862-1944) groeide op in Nederland als zoon van een rijke bankier (afb. 1). ${ }^{2}$ In 1883 vertrok hij voor zaken naar Engeland waar hij in 1886 trouwde met Maria Lydia Fraser, wier vader de Rotterdamse agent was van een Engelse reder. Door het overlijden van zijn ouders korte tijd later, kon Drucker het leven leiden van een gentleman of leisure. Verzamelen nam daarin een belangrijke plaats in, in de eerste plaats van schilderijen en aquarellen uit de Haagse school (dat begon in 1885), al snel gevolgd door Chinees porselein (in ieder geval in 1888, wellicht al iets eerder). Drucker verwierf het Britse staatsburgerschap. Hij woonde met zijn vrouw tot aan de Eerste Wereldoorlog in Londen en vervolgens in Zwitserland. Toch was het steeds de bedoeling dat de collecties in een Nederlands museum een plaats zouden krijgen. Dit voornemen zal zeker hebben meegespeeld bij de manier waarop Drucker verzamelde. In 1904 werden de eerste schilderijen in bruikleen gegeven aan het Rijksmuseum, en in 1906 volgde het eerste porselein. Voorwaarde van de Druckers was dat hun collectie in een eigen vleugel getoond kon worden. De uitbouw aan de zuidzijde van het museum - thans bekend als Philipsvleugel - was in 1916 gereed, maar vanwege de oorlog kon het porselein nog niet van Londen naar Amsterdam vervoerd worden. Uiteindelijk was de collectie in 1923 in de 'Drucker-uitbouw' te bewonderen, eerst als bruikleen en na Pown 194 als from Brill. come4/26/2023 10:14:47AM 
Afbeelding 1 Jean Charles Joseph Drucker (1862-1944). Naar een foto in de collectie van het Rijksmuseum Amsterdam

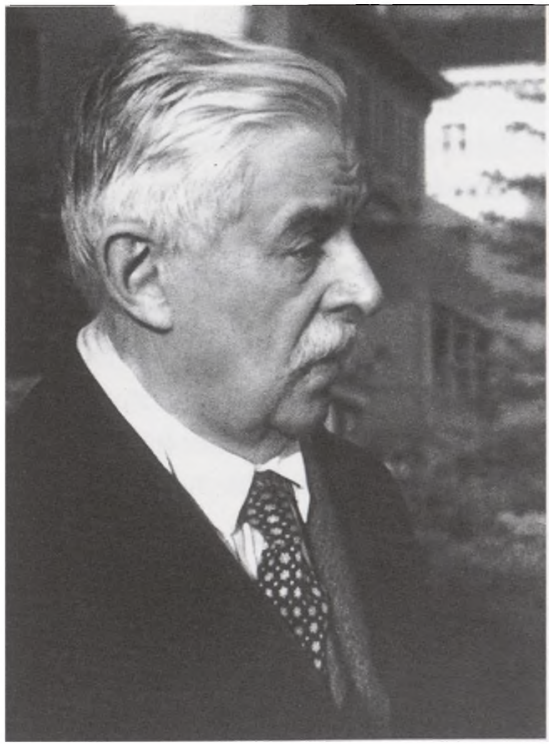

$\mathrm{Na}$ zijn vertrek naar Zwitserland heeft Drucker geen porselein meer gekocht. De collectie is dus samengesteld in de periode circa 1888-1914. Bij de aankopen was steeds de kunsthandel Arthur Tooth betrokken, een zaak die niet in porselein gespecialiseerd was, maar vooral in schilderijen handelde. ${ }^{3}$ Er werd altijd al verondersteld dat Drucker zijn porselein in Londen en omgeving kocht. Doordat in een aantal gevallen kon worden vastgesteld waar en waneer Drucker zijn zaken verwierf, wordt die veronderstelling hier verder onderbouwd. Etiketten onder stukken uit Druckers collectie, met daarop de datum van een veiling en het nummer uit de catalogus, stelden de voormalige directeur van de afdeling Beeldhouwkunst en Kunstnijverheid van het Rijksmuseum, Bram den Blaauwen, in staat de herkomst vast te stellen. Ze verwijzen naar veilingcatalogi in de bibliotheek van het Rijksmuseum. Uit inscripties blijkt duidelijk dat het Druckers eigen exemplaren zijn. Op de titelpagina staan de nummers die Drucker begeerde. Een kruisje achter het nummer gaf aan dat Tooth erin geslaagd was het stuk te kopen. Hoewel eerder wel is opgemerkt dat Drucker de opbouw van zijn porseleincollectie geheel aan Tooth overliet, suggereren deze glossen dat Drucker wel degelijk zelf keek en koos. ${ }^{4}$ De gedocumenteerde verwervingen zijn hier bijelkaar gebracht (bijlage).

Londen, 1888-1914 is een interessante plaats en periode voor de geschiedenis van het verzamelen van porselein. De tweede generatie verzamelaars was toen aan zet. In de jaren ' 60 van de $19^{\mathrm{e}}$ eeuw groeide in Engeland in het kader van de belangstelling voor historische binnenruimten al de belangstelling voor Delfts aardewerk en Chinees porselein met blauwe decoraties dat fraai uitkwam tegen donkere betimmeringen. ${ }^{5}$ Onder aanvoering van de schilders James Abbott McNeill Whistler (1834-1903) en Dante Gabriel Rossetti (1828-1882) veranderde de benadering. Met overgave werd naar het fraaiste blauw en de vloeiendste penseelstreek gezocht. Bewonderaars van Whistler en Rossetti volgden hen als verzamelaars van porselein en het verzamelen groeide uit tot een ware rage. Murray Marks (1840-1918) was de belangrijkste handelaar op dit terrein. ${ }^{6}$ Marks' vader was Nederlander en daardoor wist Murray er goed de weg. Hij kocht er porselein in voor 
'exceedingly low prices'. ${ }^{7}$ Tot de verzamelaars uit deze entourage behoort Louis Huth (1821-1905) die hier vooral ook van belang is omdat Drucker uit diens verzameling stukken kocht. Huth was bankier en verzamelaar. ${ }^{8} \mathrm{Zijn}$ vader was een Duitser die zich in Londen vestigde en de bank Frederick Huth en Co oprichtte. Louis verzamelde oude en moderne schilderijen, meubels en Chinees porselein, een combinatie die meer voorkwam en aan Drucker doet denken. Ook Drucker verzamelde naast zijn schilderijen en porselein op bescheiden schaal (niet zo erg goede) Engelse meubelen. Huths belangstelling voor Chinees porselein gaat in ieder geval terug tot 1867, toen Rosetti 50 pond voor een partij porselein te veel vond en Marks het aan Huth verkocht. ${ }^{9}$ Huth bleef een goede klant van Marks die zich van hem herinnerde dat 'he never asked the price, but as a rule (...) paid the sum that was invoiced.' 10

Nederland speelde vooral een rol als jachtterrein. Volgens Henk Budel die het verzamelen in Nederland in de $19^{e}$ eeuw nauwkeurig heeft onderzocht, hadden de Nederlanders last van een remmende voorsprong: er was 'altijd' en 'overal' zo veel Chinees porselein dat het voor verzamelen ongeschikt werd geacht. ${ }^{11}$ Engelse handelaren en verzamelaars hebben van die houding volop kunnen profiteren. Er moet een indrukwekkende stroom van porselein vanuit Nederland naar Engeland op gang zijn gekomen. 'There are so many London dealers flitting about...[rondfladderen]', schreef de porseleinverzamelaar en dagboekschrijver Charlotte Schreiber (1812-1895) op 21 mei 1876 in Den Haag. ${ }^{12}$ Schreiber reisde verwoed door Europa op zoek naar porselein (vooral ook Europees overigens) en stelde verschillende keren vast dat bij Nederlandse antiquairs teleurstellend weinig te vinden was, omdat het ingepakt was en opgestuurd naar Parijs en vooral Londen om daar te worden verkocht. Op 3 oktober 1869 bleek er bij de firma Hamburger in Utrecht niets van haar gading. 84 Kisten waren net naar Parijs gestuurd. ${ }^{13}$ Op 4 november 1872 hetzelfde probleem. 'The Hamburgers showed us through their warehouse, but there was nothing in it, as all their stock had just gone over to London, to be sold on Wednesday at Jones and Bonham's.' ${ }^{14}$ Juist omdat Schreiber in de eerste plaats geïnteresseerd was in Europees porselein, liet zij zich verschillende keren licht verbolgen uit over alle aandacht voor Chinees blauw-wit: "Blue and white" is driving everything else away' (13 mei 1878). ${ }^{15}$ Het maniakale dat sommige Engelse porseleinverzamelaars 'op jacht' in Nederland eigen moet zijn geweest, blijkt ook uit de observatie van een schoonmoeder over haar schoonzoon Cyril Flower (1843-1907) de latere Lord Battersea, die in 1874 op reis was in Holland: 'Mr. Flower is bitten with the Oriental blue and white China mania and is as difficult to tear away from any shop containing those treasures as an American lady from Worth.'16

Maar dit was de eerste generatie, de generatie die aan verkopen toe was toen Drucker aan het opbouwen van zijn collectie begon. Tot die tweede generatie behoorden een aantal serieuze verzamelaars die op zeer grote schaal kochten en daarmee de prijzen opdreven. Onder hen waren de Amerikaan James A. Garland en de Engelsman George Salting (1835-1909). ${ }^{17}$ We mogen op grond van de algemene informatie over de handelsbewegingen wel aannemen dat wat Drucker kocht van eerste generatie verzamelaars, in de voorgaande jaren voor een aanzienlijk deel uit Nederland was gekomen. In één geval wordt deze veronderstelling door extra gegevens nog iets concreter. Charlotte Schreiber merkte bij een bezoek aan restaurant De Doelen in Amsterdam op dat de fraaie vazen van blauw-wit Chinees porselein die daar tot voor kort te 
Afbeelding 2 (links) Bord, porselein met onderglazuur blauw, d. 28,5 cm., China, ca. 1700, uit de collectie van Captain Lukis, Rijksmuseum Amsterdam AK-RBK-16255

Afbeelding 3 Vaas, porselein met onderglazuur blauw, h. $28 \mathrm{~cm}$., China, ca. 1700 , uit de collectie van Captain Lukis, Rijksmuseum Amsterdam AK-RBK-16287 zien waren, nu verdwenen waren. Ze meende zich te herinneren dat ze ze gezien had op de veiling van de collectie van Captain Lukis. ${ }^{18}$ Dat was een van de veilingen waar Drucker kocht. De veiling bevatte overwegend stukken van Captain Lukis (over wie ik verder helaas niets kon vinden), maar ook een rubriek 'stukken van diverse inzenders' waaronder dus waarschijnlijk de vazen uit De Doelen.

Tot de stukken die Drucker op de veiling van Captain Lukis kocht en die karakteristiek zijn voor het porselein dat Marks en zijn collega's in groten getale uit Nederland haalden, behoort een zogenaamd 'asterbord', een bord met vijf gestileerde bloemen op een ondergrond van kleine motieven van in elkaar gedraaide lijnen (afb. 2). Eveneens zeer bekend in oude Nederlandse collecties zijn de vazen waarvan Drucker op de Captain Lukis-veiling twee paar verwierf, zeer vol beschilderd (ongetwijfeld op nadrukkelijk aandringen van de Westerse kopers in China) met banden met gestileerde ranken en draken die wit zijn uitgespaard tegen een blauwe achtergrond (afb. 3 ).

Over vrijwel geen van de personen van wie Drucker kocht (zie bijlage) kon informatie worden gevonden. ${ }^{19}$ Het waren waarschijnlijk liefhebbers die niet vooraan of voorop liepen in de 'Blue and White mania', maar tot het grote aantal volgers van die rage behoorden. Een uitzondering vormt Louis Huth die al aan de orde kwam. ${ }^{20}$ Het is interessant om een aantal van Druckers aankopen uit Huths veiling nader te bestuderen. Een opmerkelijk stuk is de vaas met velden met bloemen in famille verte ( $\mathrm{afb}$. 4). De bloemen zijn met (te) veel gevoel voor elegantie geschilderd, wat het enthousiasme voor het stuk bij mensen als Huth, nauw verbonden als hij was met estheten als Whistler en Rossetti, kan verklaren. De bloemen worden omgeven door banden met schub-motief in blauw, waarvan het schilderwerk juist nogal grof
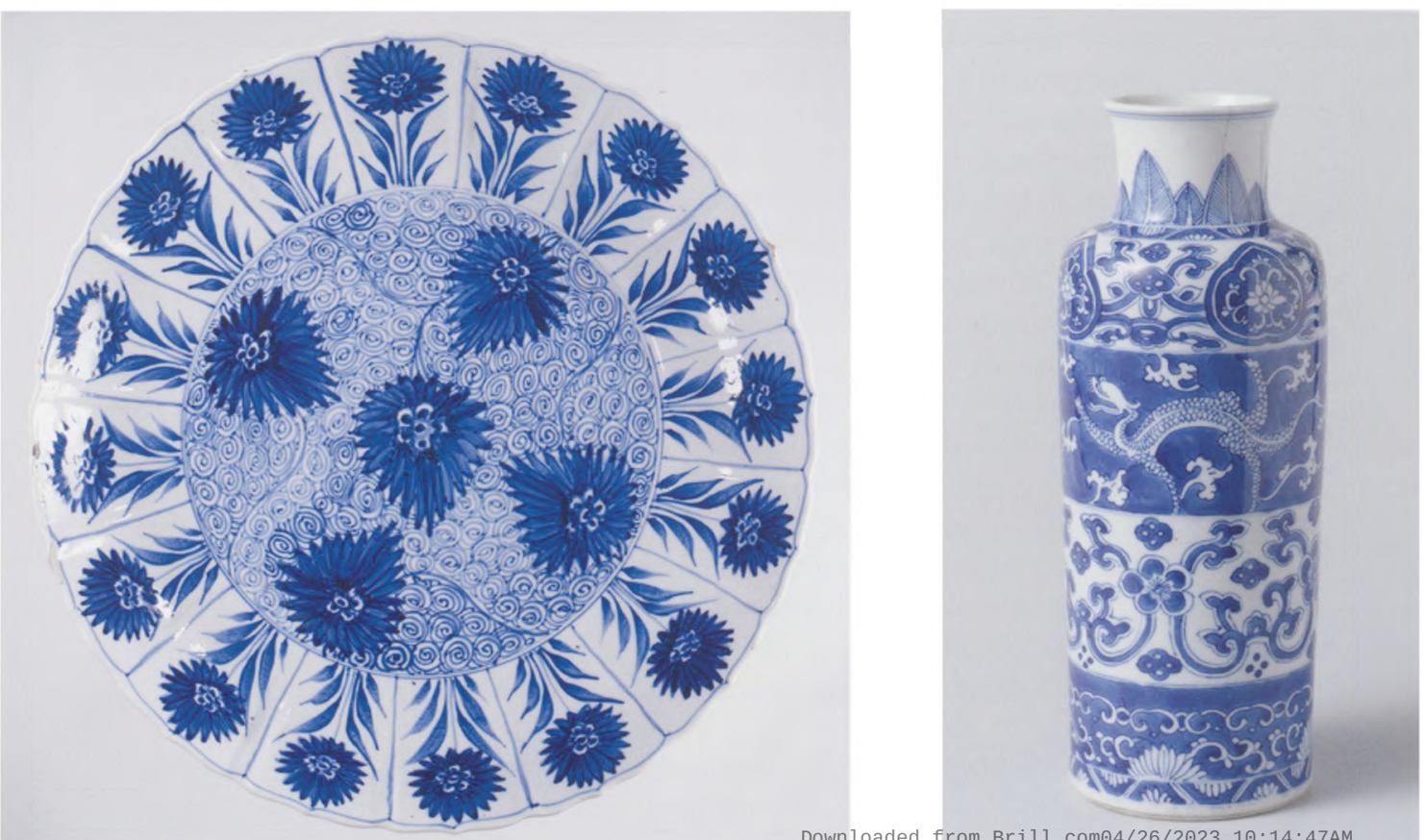


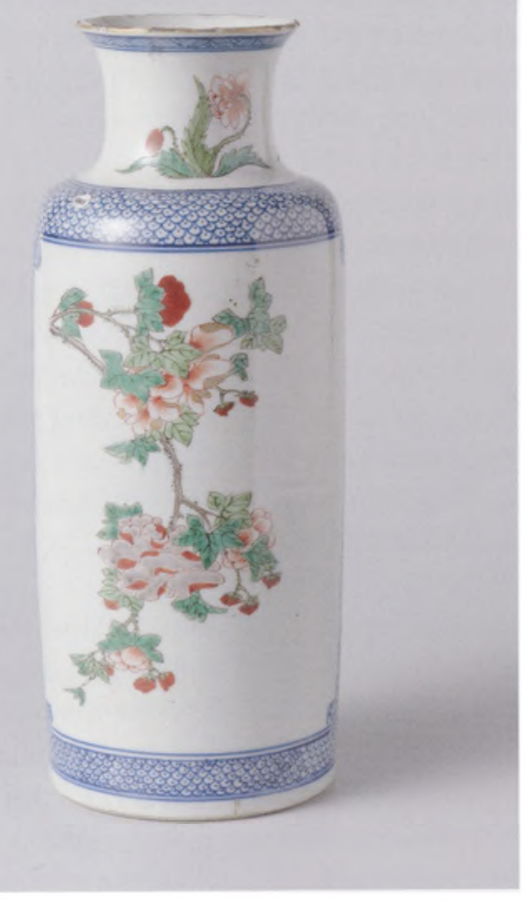

Afbeelding $4^{a}$ en $4 b$ (boven)

Vaas, porselein met onderglazuur blauw en emailkleuren, h. 27,5 cm., China, 1875-1900, uit de collectie Huth, Rijksmuseum Amsterdam AK-RBK-16367

Afbeelding $5 a$ en $5 b$ (rechtsboven) Vaas, porselein met emailkleuren, h. 21,5 cm., China, 1875-1900, uit de collectie Huth, Rijksmuseum Amsterdam AK-RBK-16293

Afbeelding 6a en 6b (rechtsonder) Vaas, porselein met emailkleuren, h. 21,5 em., China, 1770-1790, uit de collectie Huth, Rijksmuseum Amsterdam AK-RBK-16368 is. Deze ongerijmde combinatie is een goede reden ernstig te twijfelen aan een $18^{\mathbf{e}}$-eeuwse datering. ${ }^{21}$ Aannemelijker is dat het stuk geheel nieuw was toen Huth het kocht. Een tweede vaas, nu in famille rose-kleuren, was met 180 pond Druckers duurste aankoop op de Huth-veiling (afb. 5). Hier is het moeilijker te begrijpen waar het enthousiasme van eerst Huth en later Drucker vandaan kwam. Het schilderwerk is nogal grof. De lijnvoering die in het geslaagde $18^{\mathrm{e}}$-eeuwse famille rose zo fijn is en geen enkele aarzeling kent, is hier tamelijk zwaar en dikwijls niet in een rake streek neergezet. De harde kleur van de witte scherf, en de net iets te hoge hals zijn aanwijzingen dat ook dit stuk nieuw vanuit China in de Huth-collectie belandde. Van een derde vaas, met een vergelijkbare vorm, mag aangenomen worden dat hij wel uit de $18^{\mathrm{e}}$ eeuw stamt (afb. 6). Op de niet geheel gladde scherf - een karakteristiek die vaker voorkomt bij exportporselein uit deze periode - is in zeer fijne toetsen een gezelschap in een landschap geschilderd. Het is een stijl die in de ateliers die voor het hof werkten, opgang maakte in het tweede kwart van de $18^{\mathrm{e}}$ eeuw, maar later ook 'voor de markt' werd toegepast, zowel in Jingdezhen als in Kanton. Overigens werden door anderen voor andere stukken op de veiling aanzienlijk hogere bedragen betaald $\mathbf{- 5 . 0 0 0}$ pond voor een gemberpot met hagendoornmotief was het record. Drucker komt in die zin als een voorzichtig koper naar voren. Maar uit zijn opmerkelijke aanwinsten blijkt wel dat hij intussen zocht naar bijzondere stukken, die anders waren dan het doorsnee $17^{\mathrm{e}}$ - en $18^{\mathrm{e}}$-eeuwse exportporselein.

Bij een van de eerste aankopen van Drucker kwam het porselein overigens zeker níet uit Nederland. In dat geval kwam het uit oud Engels bezit. In 1888 kocht hij op een veiling van 'Old Oriental porcelain (...)' van de marquis of f $^{4: 47 \mathrm{Am}}$ 

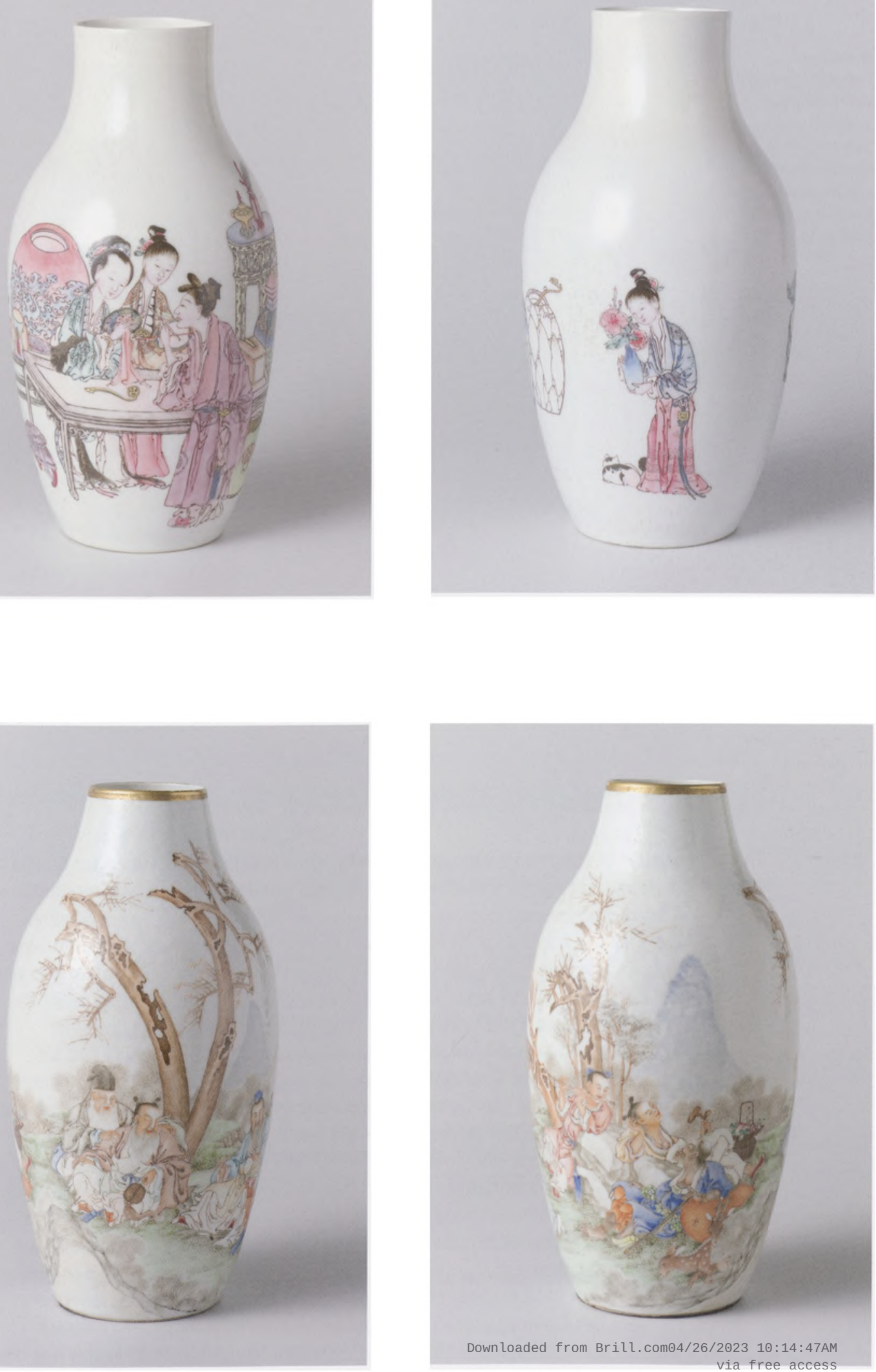


\section{Afbeelding 7}

Twee vazen, porselein met emailkleuren, h. $48,1 \mathrm{~cm}$., China, 1700-1720, uit de Burghley Housecollectie, Rijksmuseum Amsterdam, AK-RBK14283 en 14284
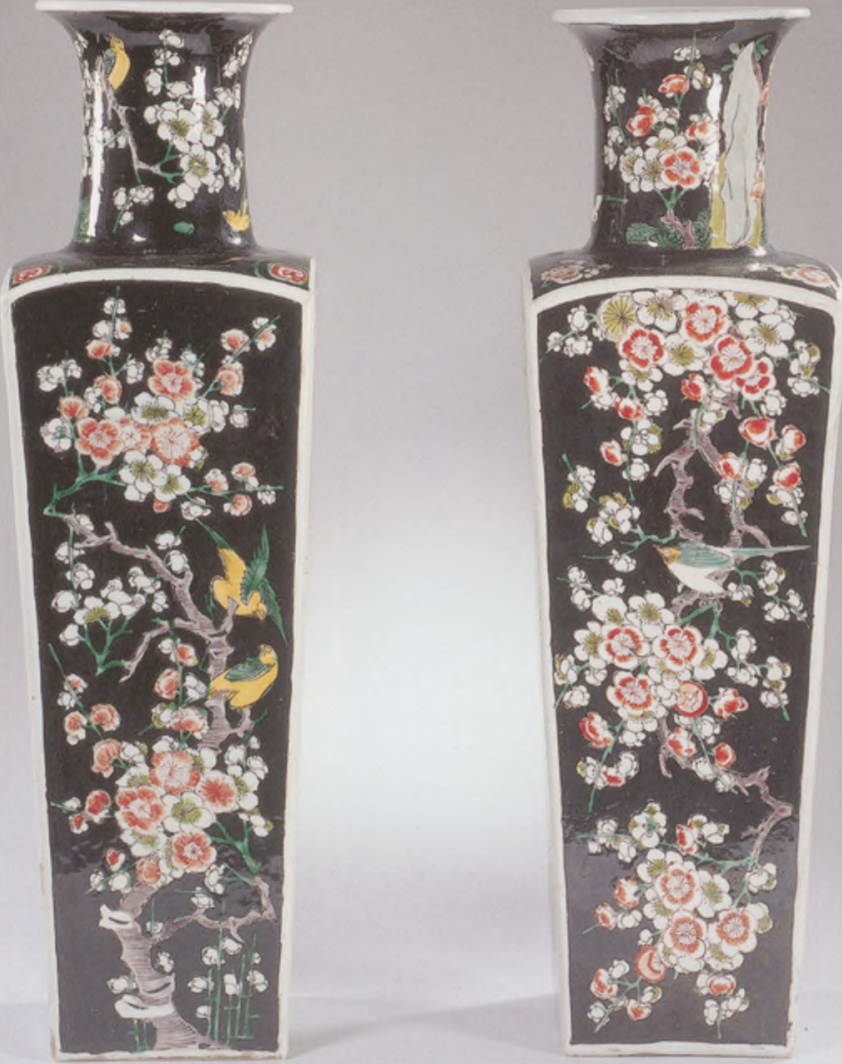

Exeter op Burghleigh House. De belangrijkste aankoop was het paar famille noire-vazen (afb. 7). Drucker kon ze relatief goedkoop bemachtigen, omdat het gerucht ging dat het vervalsingen van de Franse fabriek Samson waren. De bekende handelaar Duveen heeft Drucker later verschillende keren hoge prijzen voor zijn vazen geboden. ${ }^{22}$ De bewondering voor famille noire was aan het begin van de $20^{e}$ eeuw uitgegroeid tot een ware gekte. Drucker zwichtte niet voor de financiële verleidingen. Nadat de stukken al enige jaren in bruikleen hadden gestaan in het Rijksmuseum, schonk hij ze in 1928 ter gelegenheid van de $70^{e}$ verjaardag van koningin-moeder Emma. De vermelding hiervan in het jaarverslag van het Rijksmuseum geeft een indruk van het immense belang dat aan deze vazen en aan de schenking werd gehecht: 'Geen Europeesche verzameling zal in het afgeloopen jaar kostelijker geschenk hebben ontvangen dan onze afdeeling Ceramiek. ${ }^{.23} \mathrm{Er}$ wordt hoog opgegeven van de verfijning van de beschildering. Dat moet zijn ingegeven door de enigszins verblindende waanzin van de dag, want van het schilderwerk zou juist gezegd kunnen worden dat het opvallend grof is - spontaan zo $\mathrm{u}$ wilt. 'Door deze buitengewone gift is het Museum een van de nobelste uitingen der Chineesche Ceramiek rijker geworden (...) van onschatbare waarde voor ons land.' Later stelde Christiaan Jörg vast dat de vazen nog ond cess 
een andere reden van groot belang zijn. Ze zijn terug te vinden in een inventaris van Burghley House uit 1854, jaren voor de famille noire-rage in het Westen. Daarmee zijn het de enige bekende grote stukken famille noire waarvan met zekerheid gezegd kan worden dat ze zonder twijfel uit de Kangxi-periode stammen en niet uit de $19^{\mathrm{e}}$ eeuw. ${ }^{24}$

Druckers famille noire-vazen illustreren hoe de waardering van een object kan fluctueren: van vermeende fake, naar uiterst kostbaar particulier bezit, naar hooggewaardeerd openbaar bezit, tot half vergeten depotstuk (bij de voorbereidingen voor de bestandscatalogus die in 1997 verscheen, stonden de vazen verstoft en met een breuk aan een van de monden in depot), tot vanuit historisch oogpunt gerehabiliteerd museumstuk. De geannoteerde veilingcatalogi van Drucker bieden een mooie bron van informatie die bij een onderzoek naar een dergelijk proces gebruikt kan worden. Drucker moet een vooruitziende blik hebben gehad toen hij niet alleen zijn porselein, maar ook zijn catalogi aan het Rijksmuseum naliet.

\section{Noten}

1. Uit een ongedateerd beleidsstuk van de Vereniging.

2. E.P. Engel, 'Het ontstaan van de verzameling Drucker-Fraser in het Rijksmuseum', Bulletin van het Rijksmuseum 13/2 (1965), pp. 45-66; W. Loos, Aquarellen van de Haagse School; de collectie Drucker-Fraser, Amsterdam/Zwolle, 2002. Drucker was nooit lid van de Vereniging van Vrienden der Aziatische Kunst.

3. Arthur Tooth (1828-1900) was in 1879 een kunsthandel begonnen die door zijn vele zonen, onder wie Arthur junior, werd voortgezet.

4. 'History of the collection', in C.J.A. Jörg, Chinese Ceramics in the Collection of the Rijksmuseum, Amsterdam; the Ming and Qing dynasties, Londen/Amsterdam, 1997, pp. 11-23.

5. G. Reitlinger, The economics of taste, Londen, 1961-1970. Deel II, pp. 202-203.

6. C. Wainwright, '"A gatherer and disposer of other men's stuffe"; Murray Marks, connoisseur and curiosity dealer', Journal of the History of Collections 14/1 (2002), pp. 161-176. G.C. Williamson, Murray Marks and his friends; a tribute of regards, Londen/New York, 1991.

7. Williamson, Op.cit. (noot 6), p. 33.

8. Carp Chinese Art- research into provenance (website University of Glasgow/Burrell Collection, Glasgow).

9. Reitlinger, Op.cit. (noot 5), p. 203. Catalogue of the very choice collection of oriental porcelain, Rhodian and Damascus ware, objects of art and decorative furniture, formed by Louis Huth, esq., deceased, verkocht bij de firma Christie in Londen, 17-23 mei 1905.

10. Willamson, Op.cit. (noot 6), p. 55.

11. H. Budel, lets over Oosters porselein in de negentiende eeuw en de verzamelingen van Mello Backer en Albertus Nap (ongepubliceerde doctoraalscriptie Kunstgeschiedenis, Universiteit Leiden), 2005, pp. 37 en 39.

12. C.E. Schreiber, Journals; confidences of a collector of ceramics \& antiques throughout Britain, France, Holland, Belgium, Spain, Portugal, Austria \& Germany from the year 1869 to 1885. Red. M.J. Guest, Londen/New York, 1911, Deel I, p. 431.

13. Schreiber, Op.cit. (noot 12), Deel I, p. 44.

14. Schreiber, Op.cit. (noot 12), Deel I, p. 170.

15. Schreiber, Op.cit. (noot 12), Deel II, p. 121.

16. L. Merrill, The Peacock Room; a cultural biography, Washington etc., 1998, p. 191.

17. A. du Boulay, 'The Taft Collection of Chinese Porcelains', in: E.J. Sullivan (e.a. red.), The Taft Museum; it's history and collection. Deel II, New York, 1995, pp. 567573. De Garland-collectie is via J. Pierpont Morgan en P. A. B Widener ${ }^{26}$ grotendeels in in 
het Metropolitan Museum in New York terecht gekomen (deels ook in de Frickcollectie). De collectie Salting bevindt zich in het V\&A in Londen.

18. Schreiber, Op.cit. (noot 12), Deel II, p. 122.

19. Zij komen bijvoorbeeld niet voor in D.S. Macleod, Art and the Victorian Middle Class, Cambridge, 1996, een boek dat een uitvoerige bijlage bevat waarin de 146 belangrijkste Engelse 19e-eeuwse verzamelaars worden besproken. Evenmin komen zij voor in de gebruikelijke biografische handboeken.

20. De veiling van zijn collectie haalde de krant (The Times, 18 mei 1905, p. 10) en hij werd in 1920 opgenomen in Who was who, a compendium to "who's who" containing the biographies of those who died during the period 1897-1915, een band met bondige biografietjes waarin niet veel meer staat dan welke club de beschrevene het liefst bezocht.

21. Stellige uitspraken over de datering van porselein zijn op het moment eigenlijk niet mogelijk, zie M. Gillette, 'Replica's en vervalsingen uit Jingdezhen', Aziatische Kunst 38/2 (2008), pp. 23-39. Overigens zijn meer van Druckers stukken waarschijnlijk $19 \mathrm{e}$-eeuws.

22. Reitlinger, Op.cit. (noot 5), pp. 212-213.

23. Jaarverslag Rijksmuseum over 1928, p. 16.

24. Jörg, Op.cit. (noot 4), nr. 220.

\section{Bijlage: herkomstgegevens collectie Drucker $\mathrm{CL}=$ Christie Londen}

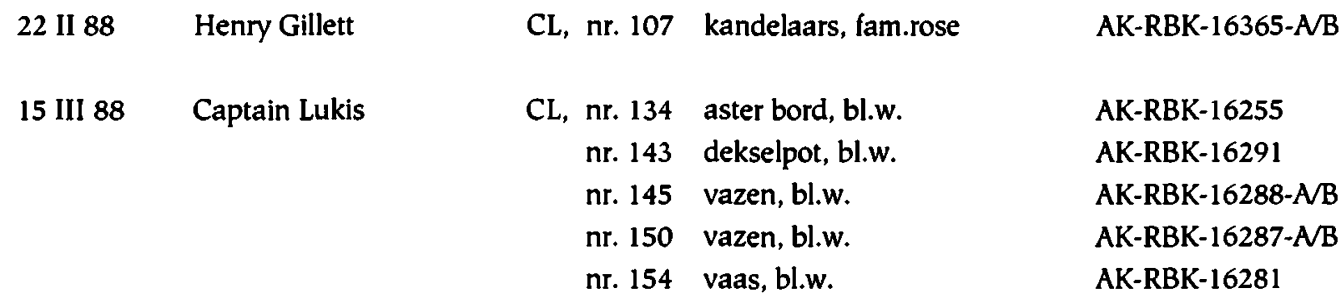

14/7 IV 88A. Andrews, Londen

CL, nr. 267 kan, fam. verte

AK-RBK-16332

24 IV 88 William Rennie, Londen

$\mathrm{CL}$, nr. 175 vaas, fam. verte

AK-RBK-16335

nr. 174 rolwagen, fam. verte

AK-RBK-16343

nr. 178 knobbelflessen, fam. verte

AK-RBK-16345-AB

7/8 VI $88 \quad$ Marquis of Exeter Burghley House

\section{$20 / 23$ VI 88}

William Lee
Downside Leatherhead

CL, nr. 248

nr. 257

nr. 256

paar vazen bl.w.

vaas, bl.w.

kaststel, bl.w.

CL, nr. 95 vaas, bl.w.

25 II $90 \quad$ Anoniem
AK-RBK-16324

AK-RBK-16319-AB

AK-RBK-16351

AK-RBK-14283/4

AK-RBK-16253-AB

AK-RBK-16278

AK-RBK-16284

AK-RBK-16261

13 VI 92 '84 Brook Street', Londen CL, nr. 199 dekselpot, fam. verte

AK-RBK-16347 


14 IV $93 \quad \begin{aligned} & \text { C.A. Whitehead, } \\ & \text { Manchester }\end{aligned}$ CL, nr. $67 \quad$ vissenkom, bl.w. $\quad$ AK-RBK-16264

18 IV 96 Anoniem CL, nr. 114 schotel, fam. verte

AK-RBK-16373

4/10 III 96 Sir Edward J. Dean Paul CL, nr. 190 schotel, fam. verte

AK-RBK-16322

16/17 III 96 Anoniem

CL, nr. $35 / 6$ schaal fam. verte

AK-RBK-16328/16356-AB/C

nr. 57 schotel, famille verte

AK-RBK-16348 7 pond

Opmerking: volgens titelpagina veilingcatalogus: 'Old Chinese porcelain the property of a well known collector'
29 V $99 \quad$ Anoniem
CL, nr. 105 beker, fam. verte

AK-RBK-16363

3/4 III 00 Mrs. Bloomfield Moore, CL, nr. 200 kan en bekken, fam. verte

AK-RBK-16330-AB

Londen

Opmerking: vermoedelijk, geen geannoteerd exemplaar van de veilingcatalogus gezien
7 VI $00 \quad$ Anoniem
CL, nr. 4 kandelaars, bl.w.
AK-RBK-16308-AB

Opmerking: vermoedelijk, geen geannoteerd exemplaar van de veilingcatalogus gevonden

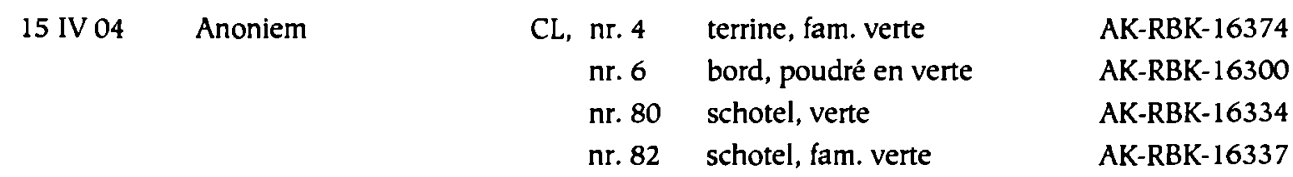

22 IV 04 Fountaine collection $\quad$ CL, nr. 19 schalen, fam. verte AK-RBK-16359-AVB

14 IV 05 Anoniem CL, nr. 6 schotels, bl.w. en verte AK-RBK-16331-AB 25 pond

18 IV 05 Anoniem CL, nr. 146 schotel, fam. verte AK-RBK-16333

$17 / 19$ en Louis Huth

$22 / 23 \mathrm{~V} 05$
CL, nr. 46 penseelpot, fam. verte
nr. 47 tafeltje, email sur biscuit
nr. 334 vaas, fam. verte
nr. 354 vaas, fam. rose
nr. 355 vaas, fam. rose
AK-RBK-16341 28 pond
AK-RBK-16318 52 pond
AK-RBK-16367 89,5 pond
AK-RBK-16293 180 pond
AK-RBK-16368 70 pond

$18 \mathrm{~V} 08$ Anoniem (lady of Title) CL, nr. $66 \quad$ vaas, poudré en verte

AK-RBK-16296-AB 280 pond

7/9 VI 10 collectie T.W. Waller CL, nr. 353 fles, fam.verte

AK-RBK-16320 73 pond

20 VI 10 Anoniem

CL, nr. 104 boeddh. leeuwen,

email sur biscuit

nr. 107 papegaai, email sur biscuit AK-RBK-18006 21 pond

24 II 14 Anoniem CL, nr. 20 vaasje, fam. verte

AK-RBK-16371 6 pond

10/11 VI 14 Anoniem CL, nr. 45 papegaaien, email sur biscuit AK-RBK-16326

Opmerking: 'the property of a gentleman who has disposed of his London Residence [in handschirt Drucker bijgeschreven:] Leonard Clow' 